\title{
Novel mouth guard for safe endoscopy in the COVID era
}

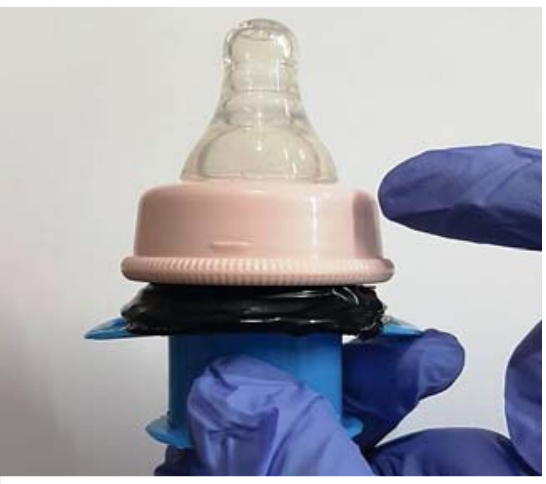

- Fig. 1 Attach the upper part of a baby's feeding bottle to the mouth guard.

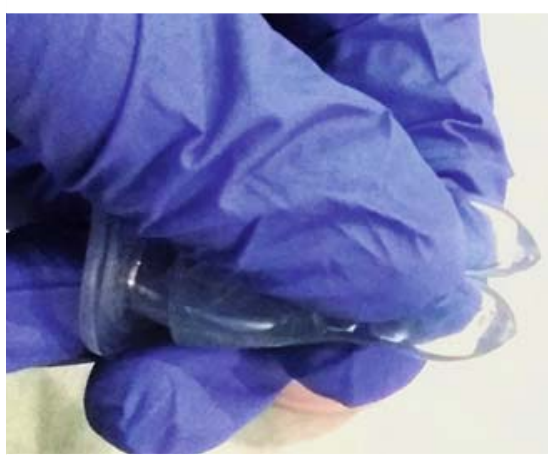

- Fig. 2 A silicon nipple with a slit functions as a valve.

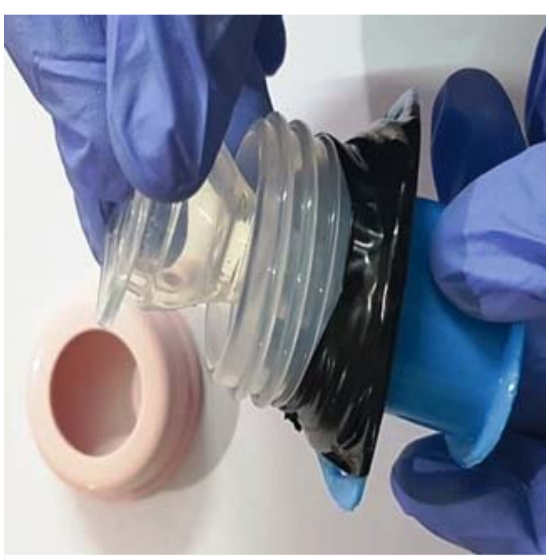

- Fig. 3 Invert the nipple into the bottle neck and screw down the collar.

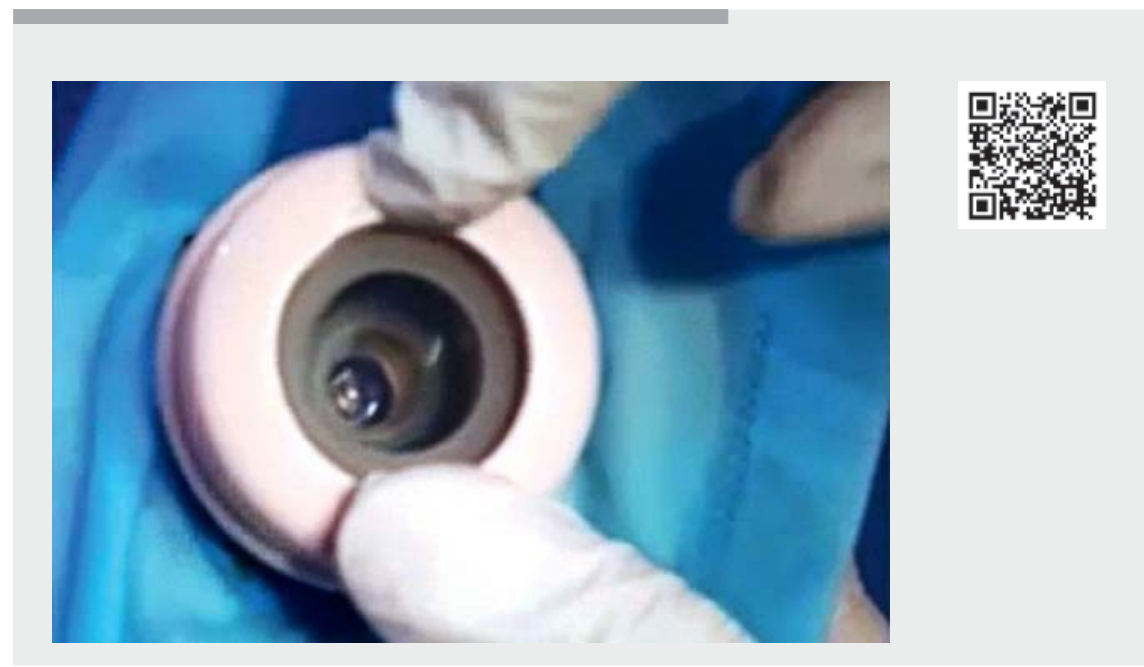

Video 1 Novel mouth guard for safe endoscopy.

COVID-19 is a disease caused by a novel coronavirus (SARS-CoV-2), which is chiefly transmitted through respiratory secretions, aerosols, and contaminated surfaces [1].

Endoscopy is an aerosol-generating procedure and thus carries a significant risk of transmission of aerosol-borne diseases to the endoscopist and staff [2]. During endoscopic procedures, a wide open space is left between the mouth guard and the endoscope, through which large quantities of aerosols escape, increasing the risk of infection.

We have made a few changes in the mouth guard to prevent exposure to aerosols and allow endoscopy to be carried out safely. The elements of the novel mouth guard are: a standard mouth guard, a baby feeding bottle, a feeding bottle nipple, and a triple-layer mask ( Video 1).

Take a plastic feeding bottle and cut off the upper end at the neck. Fix this upper end of the bottle to the mouth guard ( $\triangleright$ Fig. 1). Then take the nipple and make a small slit across its top ( $>$ Fig. 2 ). Invert the nipple ( $\triangleright$ Fig.3), place it in the bottle neck, and screw down the collar tightly

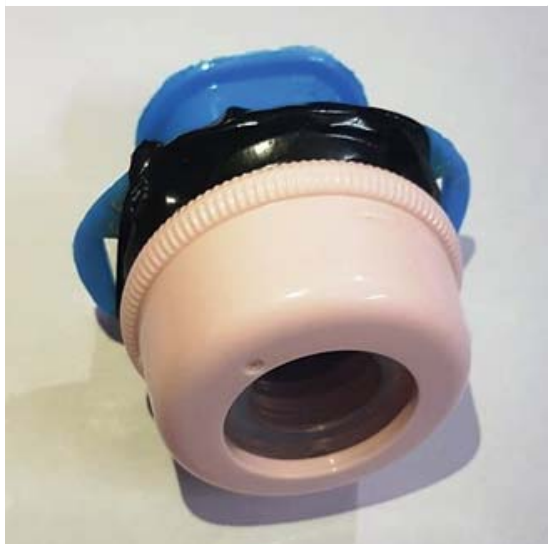

Fig. 4 Perspective view of the novel mouth guard.

(ฉ Fig.4). Then take a surgical mask, cut a hole in the middle of it, and fix the assembly into the mask ( $\mathbf{F i g . 5}$ ).

Place the novel mouth guard inside the patient's mouth and perform endoscopy with all due precautions and necessary protective equipment. The nipple inside the device acts as a perfect valve and prevents aerosols from escaping ( $\triangleright$ Video 1 ). We have been able to carry out both diagnostic and therapeutic endoscopies with 


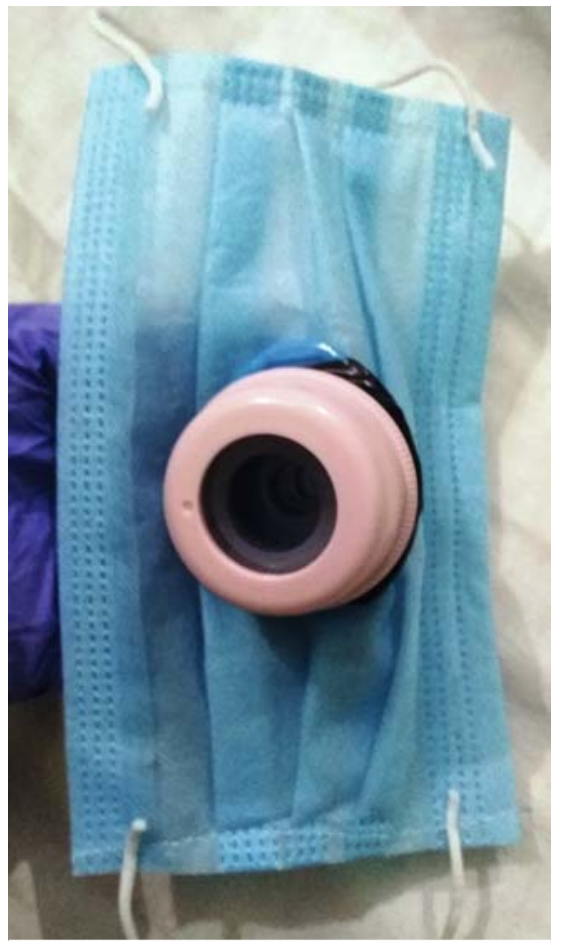

- Fig. 5 Novel mouth guard in place in a triple-layer mask, ready for use.

these changes. We have demonstrated the efficacy of our device by performing a simple experiment simulating endoscopy and aerosol generation ( $\bullet$ Video $\mathbf{1}$ ). Our device is cheap, easy to make, reusable, and allows us to do endoscopy more safely during this COVID era.

Endoscopy_UCTN_Code_TTT_1AO_2AN

\section{Acknowledgments}

We thank Mr. Kuldeep Singh Katiyar for editing the video.

\section{Competing interests}

The authors declare that they have no conflict of interest.

\section{The authors}

\section{Sachin Dev Munjal ${ }^{1}$, Yogita Munjal ${ }^{2}$}

1 Department of Gastroenterology, Gastro Liver Care Hospital, Saharanpur, Uttar Pradesh, India

2 Department of Histopathology, Gastro Liver Care Hospital, Saharanpur, Uttar Pradesh, India

\section{Corresponding author}

\section{Sachin Dev Munjal, MD}

Department of Gastroenterology, Gastro Liver Care and Saksham Hospital, Saharanpur, 247001 Uttar Pradesh, India gastro.liver.help@gmail.com

\section{References}

[1] del Rio C, Malani PN. COVID-19 - new insights on a rapidly changing epidemic. JAMA 2020; 323: 1339-1340

[2] Johnston ER, Habib-Bein N, Dueker JM. Risk of bacterial exposure to the endoscopist's face during endoscopy. Gastrointest Endosc 2019; 89: 818-824
Bibliography

Endoscopy 2021; 53: E238-E239

DOI 10.1055/a-1308-0778

ISSN 0013-726X

published online 17.12 .2020

(C) 2020. Thieme. All rights reserved.

Georg Thieme Verlag KG, Rüdigerstraße 14, 70469 Stuttgart, Germany

\section{ENDOSCOPY E-VIDEOS}

https://eref.thieme.de/e-videos

回回 Endoscopy E-Videos is a free 整视 靣转: on interesting cases and new techniques in gastroenterological endoscopy. All papers include a high quality video and all contributions are freely accessible online.

This section has its own submission website at https://mc.manuscriptcentral.com/e-videos 